\title{
THE APPLICATION OF ART IN THE ENHANCEMENT of SPEAKING SKILls IN GREeK State Primary SCHOOL STUDENTS OF PRE-A1 LEVEL
}

\author{
Eirini Kikioni ${ }^{1}$ and Makrina-Nina Zafiri $^{2}$ \\ ${ }^{1}$ Ministry of Education and Religious Affairs, Greece \\ ${ }^{2}$ Aristotle University of Thessaloniki, Greece
}

\begin{abstract}
The findings show that visual arts-based instruction positively impacts learners' oracy abilities, vocabulary development, and formulaic assimilation. Art has always been a potent medium for teachers of all subjects contributing to learners' social, emotional, intellectual and physical evolution. However, it often becomes subjugated and considered as unnecessary and extracurricular. The particular research aims at exploring the ways Art can be integrated into the first grade of Greek State Primary School curriculum for English language learning and exploited for the benefit of young learners. More specifically, this research aims to investigate whether art, and particularly visual arts, can emerge as an invaluable tool which will enhance instruction for the learning of English as a foreign language, thus triggering motivation which will lead to young learners' enhancement of their speaking skills. In addition to this, this research explores the effects of visual arts-based instruction on vocabulary, and language chunks development, through young learners' engagement in a number of multisensory tasks deriving from works of art presented to them. For this reason, action research was carried out among thirty-two first grade learners of a state primary school in Greece, who were divided into two groups, a control and an experimental group. The information obtained through both quantitative and qualitative tools of data collection will be exploited for this research as they can prove that the participants of the experimental group improved substantially concerning all the three variables compared to the participants of the control group. The results of this small-case research cannot be disregarded as they indicate that the use of visual arts can have a considerably positive effect on young learners' receptive and productive oracy skills.
\end{abstract}

\section{KEYWORDS}

oracy skills, vocabulary development, language chunks development, visual arts, young learners

\section{INTRODUCTION}

"The development of the speaking skill is of vital importance in English language teaching" [1], as an effective communicator constitutes a key-part of being a successful language learner [2]. The importance of its instruction, especially from a very young age has been emphasized by various researchers throughout Europe and Greece [3] as, according to Brown and Yuke (1983), "speaking is the skill that the students will be judged upon most in real life situations" [4]. Given the "ever-growing needs for fluency in English around the world as a consequence of the role of English as the world's international language" [5], and taking into consideration the specific characteristics of very young language learners which create a need for playful and unorthodox methods to English language learning [6], emphasis is placed upon finding more effective ways to introduce them to the oral mode of the language and to teach them "the functional and communicative potential" of it [7]. 
Art, and more specifically visual arts, constitute an invaluable tool that may enhance instruction for the English language although it sometimes becomes subjugated as it is considered unnecessary. However, a considerable amount of research has shown that with reference to the development of the speaking skill, pieces of art such as paintings can be used as prompts for wonderful speaking opportunities [8] triggering imagination and visual awareness. Bearing in mind that not much research has been conducted in Greece, concerning art and the teaching of English to very young learners, the particular research aims to indicate how visual arts may emerge as a tool to immerse young learners in speaking activities that may enhance their ability to use the target language.

The research papers which were presented were selected according to their similarity in their content to the research conducted by the researchers of this paper.

\section{The Use of Visual arts in Speaking: A Multisensory ACtivation, Vocabulary Development and Formulaic UPTAKE TOOL}

Teachers increasingly incorporate art in their syllabi in order to facilitate learners to master the required capacities and content knowledge areas, offering learners outlets for active exploration, and hands-on learning experiences [9], [10]. The subject of whether exposure to visual arts can improve the language awareness of very young learners appears to be within the area of research conducted by Stanford University [11]. More specifically, the aforementioned study investigated whether artistic display, of this kind, could lead young learners to improve in their skills such as reading, writing, and verbal communication. Also, Kennedy [12], in his review of a Guggenheim assessment of an art education program in New York public schools, pin-pointed that young learners' involvement with visual arts, such as paintings, and sculptures, has had a positive impact on the development of their literacy and oracy skills, thus aggrandising art to the point where it finally became an essential part of the English Foreign Language (EFL) curriculum.

More specifically, given the importance of visual communication in real life [13], as well as the need young learners have to become furnished with rich visual stimuli, in order to acquire a motivation, and to become engaged in the learning process [14], the specific study aims to offer diverse approaches on how teachers of English can exploit visual arts to enable young learners of pre-A1 level to understand the world they live in and to find avenues for sophisticated comprehension and communication [15]. Situating visual arts within the context of the lives of young language learners and encouraging them to verbally express themselves by observing and responding to the artworks presented, the particular research aspires to investigate how learning English, as a foreign language, may become more meaningful and relevant to learners, at this early stage.

Espousing Communicative Language Teaching's (CLT) fundamental premises, the development of well-rounded learners and enlightened citizens is targeted through the learners' attempt to perceive and respond to visual forms linking art to the primary goal of personal fulfillment [16]. The syllabus for English, as a foreign language teaching and learning, for the age group and language level, under scrutiny, also complies with the PEAP (the English for Young Learners Programme in Greek Primary Schools) curriculum's basic principles which highlight the social and cultural basis of learning, following a learner centered approach to language teaching [3]. In the present research study, examples are provided of the teacher's attempt to develop activities which are geared towards motivating and educating learners, as a whole, while at the same time they enhance language acquisition. Being in total agreement with the socio-cultural framework embracing the aforementioned curriculum, visual arts can be used as a tool to express global 
International Journal on Integrating Technology in Education (IJITE), Vol.10, No.4, December 2021

experiences and to help to remove biases [10]. Young learners are allowed to learn about themselves and others by viewing and assessing artistic content, whereas sensory experiences, triggered by visual stimuli, elevate understanding of the human experience [10], thus enhancing social awareness and intercultural communicative competence. Art is established as the remedy to curricular malaise [17] whereas learners' social literacies are enhanced by focusing on the social nature of speaking.

\subsection{Integrating Visual Arts into an EFL Curriculum: Benefits}

Given the importance of art in the teaching of English as a foreign language, incorporating visual arts into the curriculum is recommended, with the primary goal of benefiting young learners socially and linguistically. Through the investigation of aesthetic components that can be employed in the classroom to trigger sensory cues and to motivate students [18] the lesson can be conducted more effectively. At the same time, artistic elements that can actively be used in the class, can lower foreign language learning anxiety [19]. Taking the aforementioned into consideration, the purpose of this particular research is to increase first grade learners' skills in using the spoken language by enhancing vocabulary development and formulaic language use.

\subsubsection{The connection of Visual Arts to the development of speaking}

Considering oral language development, as a powerful precursor to fluency [20], it is imperative to acknowledge that visual arts may serve as a referent for oral language production and conversation among learners. This article investigates how young learners' interaction with visual arts can lead to "increased participation and meaningful speech production" [18], in foreign language learning [21], [18]. Providing positive and relevant "input, art encompasses what may be tangible and imagined" [22], allowing learners to feel at ease and open to acquisition (to feel at ease in the English class) [23], while also encouraging them to actively participate in the learning process [10].

Given that young learners perform better in an enabling environment [24], visual art, "whether modern, classic, minimalist, or renaissance art, can serve as a great stimulus for developing productive abilities and engaging learners in more meaningful and memorable experiences" [18]. Inviting learners to recognize items, colors, or moods, in a painting, or wallowing in creating stories, of what they see can spark motivation, whereas their dialogic interaction with a piece of art may engender purposeful communication leading to the development of oral language competence [25]. Fostering curiosity by entailing abound information to be unveiled, visual arts "create a need for language, allowing learners lacking the necessary vocabulary to communicate being supported by the teacher and to move to the next step of linguistic development through scaffolding" [13] favoring at the same time an interactive approach to language learning [3].

Exposure to art and artistic expression aims to make learning English as a foreign language more enjoyable and meaningful by including students in follow-up activities using various types of art, such as drawings or crafts, that are related to the pieces of work to which they are exposed to. More specifically, the multiple intelligences which are present in a typical group of first graders [22], are stimulated, and opportunities are allowed for everyone to join the specific course of learning. Paintings are made of specific materials, and authentic paintings, when utilized in the teaching of English as a foreign language, emphasize the students' awareness of their current surroundings which include the environment of others. Young learners are attracted by the physicality of the paintings and when confronted with works of art they attempt to interpret what they see, this attempt will offer them favorable circumstances for language learning and development, sometimes even unintentionally [26]. 
International Journal on Integrating Technology in Education (IJITE), Vol.10, No.4, December 2021

Furthermore, learners' social attitudes are improved as a result of introducing them to the concept of creativity through art, which allows for better levels of knowledge [27]. Learners' intellectual and social potential is enhanced when they are engaged in a play-like lesson that relates to reallife through their interaction with the paintings and each other [28], whereas the use of visual arts can effectively moderate learners' shyness in the class and engage them in taking on the challenge of speaking English [29].

\subsubsection{The connection of Visual Arts to multisensory activation and oral development}

Taking into account that teaching foreign languages, to very young learners, is a challenging process where specialized steps and actions are necessary, the present study also examines how visual arts encourage young learners, at this early stage, to use some or all of their senses to become actively engaged in the learning process enhancing oral development through random word building and formulaic uptake [30].

"Synesthesia (Greek, syn $=$ together + aesthesis $=$ perception $)$, defined as the involuntary physical experience of a cross-modal association which occurs when the stimulation of one sensory modality evokes a perception in one or more senses" [31] is activated through learners' exposure to the physicality of the paintings. Through this exposure different sensations are deliberately linked permitting enhanced data acquisition [31]. In this context, assuming that young learners learn better when the information received is physically, audibly, and visually integrated by using all senses [32], multi-activity environments, in which learners can interact with a range of paintings, are suggested. The need to create a livelier teaching environment through the application of activities aimed at oral production, activated by sensorial stimuli [18] is addressed in the specific study, based on the hypothesis that learners can "learn better from information taken in through their basic senses" [18].

Learners' different receptive channels are activated through visual arts-based activities that use a mixture of senses such as hearing, sight, smell, taste, self-movement, and touch as a tool to deliver language instruction [33]. This allows for more cognitive connections and associations to be made with the new input that is being introduced. Young learners spend enough time being exposed to language through different channels of perception as a result of being invited to interact with the paintings using all of their senses, resulting in the unintentional production of simple sounds and structures in the target language [13]. Finally, using several sources of information to channel knowledge responds to the many learning styles of young learners [21] and piques their interest in learning. It also intends to investigate how using multimodal learning strategies to enhance young learners' interactions with artworks allows them to engage more deeply with the subject and helps them to remember information for longer periods of time [34]. Finally, it tries to make it easier for students to master abstract language and to improve their oracy abilities, which is this study's main aim [28].

\subsubsection{Visual Arts as a tool to enhance vocabulary development}

Learners' ability to use English improves greatly when they learn more words. Indeed, since the CLT approach was introduced, vocabulary acquisition has become a primary emphasis of linguistic work as a necessary precondition for communication. As suggested by reference [35], "real vocabulary learning comes through use, meeting the words in a variety of contexts and having to use them to express new ideas", while lexical competence is placed at the heart of the communicative competence [36]. 
More precisely, young learners at this age are extremely attentive and appear to absorb language offered to them like a sponge [37], which helps them to develop their oral skills and their speech output. Nonetheless, no matter how effective this group's memorization skills appear to be, they still prefer to remember and use just what makes sense [37], [38] emphasizing on the need for learners to receive appropriate language exposure on a regular basis. Furthermore, the limited attention span and discipline issues that characterize the age group under investigation call for more spirited and unusual approaches to foreign language learning, establishing visual arts, which are characterized by a variety of colors, lines, and shapes, as the ideal springboard for learning [39]. Visual arts, characterized by physiological features and usually an intriguing perception of the world [31], may be used as a lively canvas for encountering new words, as opposed to decontextualized pictures or flashcards suggested by the curriculum, at issue, for the introduction of new vocabulary enabling students to form a strong memory link between visuals and words and, eventually, to employ the appropriate words [40].

The relevance of linking a word to an object or a living person in a painting is emphasized while learning a foreign language, and this is one of the key reasons why visual arts, which are characterized by rich visual stimuli, are crucial in early language settings [37]. In fact, contrary to the curriculum's tendency to use isolated flash cards to present linguistic input out of context, paintings can be viewed as a mnemonic tool to aid "long-term consolidation of linguistic content" [41], whereas observing and interpreting visual arts such as paintings and elaborating on them can be an excellent way to elicit new vocabulary and to aid learners to build their lexicon [18]. Responding to a picture can be interesting for young learners and can lead to a variety of exercises that are intended to improve lexical competence while also encouraging learner autonomy and integration of communication skills. Learners are encouraged to make educated guesses and to infer meaning from what they perceive, thus improving comprehension and retention of content [42].

Furthermore, because true learning occurs when someone creates a personal interpretation of what is presented [43], this study will examine whether learners' artistic production which is related to the content which has been presented to them can improve their motivation, their receptive, and productive vocabulary development, and whether it can also active their undivided participation in an EFL class. Finally, it is suggested that emphasis should be placed on learners' demonstration of acquired linguistic knowledge derived from the paintings rather than the aesthetic elements of artistic production, and that learners should be encouraged to make conscious choices of content and form in order to achieve better vocabulary learning results [10]. As a result, it appears that in order to establish an appropriate instructional framework for teaching the speaking skill to pre-A1 learners, it is necessary to provide them with rich and authentic visual stimuli associated with visual arts in order to introduce new vocabulary and also to familiarize them with a more colloquial use of the target language through their multisensory engagement with the paintings.

\subsubsection{Visual Arts as a tool to enhance language chunks development}

The fundamental goal of foreign language learning in primary school in Europe is to improve young learners' communicative capacities, with a focus on the development of oral skills such as listening and speaking [30], [44] and [3]. The emphasis is placed on learners' familiarity with the use of lexical chunks and phrases, in accordance with the principles of CLT, which accommodate for opportunities for young learners to use the language spontaneously.

Young learners should be encouraged to utilize a fixed repertoire of lexis and set phrases, which will subsequently serve as a foundation for future language learning and use as a result of their participation in a variety of situational activities such as structured conversations and role-playing 
International Journal on Integrating Technology in Education (IJITE), Vol.10, No.4, December 2021

[3]. Young learners, in particular, should be given the opportunity to practice language patterns and take command of basic communication settings by employing simple rote-learned words and regulated output. However, while these types of activities may inspire first-graders to participate in the learning process, most of the activities offered by the curriculum, at issue, appear to be lacking in possibilities to experiment with the language and to move beyond the fixed dialogues.

This research seeks to demonstrate how young learners can be helped in an attempt to launch language use beyond equations and reproduction by suggesting a method for creative speaking activities related to learners' sensorial contact with the visual arts [44]. It also seeks to figure out how exposing young learners to visual arts can help them gradually build the necessary abilities for more autonomous language use. Maintaining young learners' excitement and enthusiasm for the foreign language, requires providing opportunities for them to discover and experiment with the language in a meaningful linguistic environment, which is given, in this case, by visual arts.

According to Lewis (1993), rather than drilling, lexical chunks and phrases should be "contextualized and implicitly taught through meaningful activities" [45]. To this purpose, a painting's content might be compared to real-world settings, into which students can immerse themselves by constructing stories and identifying with the scenarios represented. This allows for the creation of "real operational conditions" [14], which allow learners to process authentic acquisition of the foreign language and to become communicatively competent.

Because the development of fluency and speaking competence requires more than memorizing chunks of language [44], it is critical to recognize that learners are given the opportunity to become linguistically creative in constructing larger chinks of oral language through their multisensory enactment with visual arts [38], [44]. Through their attempts to interact with the paintings, learners' physiologies, emotions, and cognitions are activated, and they are guided to a meaningful production of language, thus managing language as a whole [45].

Smell, taste, and physicality define visual arts, which inspire creativity while offering a superb framework for presenting multi-word units to learners, thus allowing for language production, and improvement of their comprehension [46]. They may emerge as a useful technique to "allow learners to correlate expressions learned with a mental image of a physical scene, facilitating retention in long term memory" since they depict moments in time [47]. Visual arts, with a fiction quality, allow students to "form and process lexical understandings which have an imagistic (visual, haptic, kinaesthetic or other perceptual) component" [48] whereas "such encoding of a verbal form with semantically imagery seems to provide an extra pathway for recall" [47]. Young learners are encouraged to create a mental lexicon of formulaic units as a result of their involvement with visual arts, which may play a key role in lowering the processing work required for language production [46].

\section{Materials ANd Methods}

The aim of this study was to see to what extent young learners' speaking skills might be improved by including visual arts, which would eventually lead to greater communicative abilities.

The research questions which were posed in this study were founded upon the notion that learners learn better when their basic senses are engaged by the use of VAs:

1. How do visual arts enhance speaking skills in first grade learners?

2. How do visual arts enhance vocabulary learning and use in first grade learners?

3. How do visual arts enhance chunks of language learning and use in first grade learners? 
International Journal on Integrating Technology in Education (IJITE), Vol.10, No.4, December 2021

\subsection{The Research Design: Conducting Action Research}

The specific research uses action research to answer the issues mentioned above, which involves four sequential stages of investigation [49]:

(1) "Clarifying visions and targets" - The researcher identifies a topic worthy of a busy teacher's time and clarifies goals.

(2) "Articulating Theory" - The Researcher identifies variables such as values, beliefs, and theoretical perspectives relating to their focus.

(3) "Implementing Action and collecting data" - Theory of action is implemented and data is collected.

(4) "Reflecting on the data and planning informed action" - The researcher methodically sorts and examines data and then reports to research.

The researchers chose this method of research for a variety of reasons, the most crucial is that action research is relevant to the needs of the participants [49], because it is "carried within the context of the teacher's environment and it allows for coping with educational matters at hand" [50]. Second, it is extremely valuable to educators since it represents a desire for information about how to enhance their teaching techniques and to help their students to develop [50], [49]. Finally, it allowed for the use of both quantitative and qualitative methods of data collection with a view to achieving triangulation of results and "strengthening research findings by using multiple ways to collect and analyze data" [51]. An experimental design was advocated in order for the specific research to be carried out, with participants divided into two groups: the experimental and the control group.

\subsection{The participants}

The participants in this study were 32 monolingual students in the first grade of a primary school in Greece, who were divided into two groups. The bulk of the students had never been taught English as a foreign language before, and their skill level was pre-A1 (Council of Europe, CEFR, 2017), indicating that they were at the beginning of their language learning journey. Because this was the learners' first encounter with the target language, the levels of the two groups were assumed to be similar, and they were assigned to the control and experimental groups at random.

\subsection{The procedure}

The program began in the first week of October 2020 and ended in the first week of February 2021. It was divided into three stages: the pre-instruction, the instruction, and the post-instruction stage which were all appropriate to learners' needs and interests. In addition, to both groups of participants, a pre-instruction vocabulary test and a language-chunks test was conducted to determine their degree of oral comprehension in relation to simple vocabulary forms and uptake of formulaic language. This test was piloted earlier to 5 students, because it was a selfconstructed test, not a standardized one. The test was conducted to the group, of the aforementioned group of 5 students, so as to see whether its contents were clear to all students of this age group and language level and whether changes should be made. Fortunately, no problems arose.

Both groups received eleven teaching lessons which related to six separate thematic areas which are included in cycles B and C, of the PEAP Curriculum's proposed material, throughout the instruction stage. The experimental group received eleven teaching lessons of art-based training, whereas the control group received standard instruction based on the PEAP curriculum's recommended learning material. They were given flashcards and movies to expose them to the 
various topics, and they were encouraged to practice the speaking abilities that the material promoted. The artworks, which were used as prompts in the experimental group, were chosen based on their thematic connection to the curriculum's specified topics. In addition, at the end of each theme area, participants in both groups were required to undergo while-instruction tests. All learners were required to complete a post-instruction vocabulary and language-chunks development test at the post-instruction stage. Both tests were identical to the ones that learners had to take before starting the program. For the analysis of the results obtained through the quantitative research tools the Statistical Package for Social Sciences (SPSS 2.1.0) was used.

Also, the participants of the experimental group had to respond to a post-semi structured interview which aimed at disclosing the degree to which learners had been aided by art-based instruction with reference to the development of oracy skills. Teachers' diaries (which answered to very specific criteria) were also kept by the researchers for the experimental group during the whole instruction stage, whereas the delivery of the lessons and the tests, as well as the interview taking, were recorded with the help of an audio digital recording machine.

\section{THE Findings}

\subsection{Research Question 1: How do visual arts enhance speaking skills in first grade learners?}

According to the data gathered from the teachers' diaries, the audio recordings of the classes, and the post-semi structured interview given to the experimental group's participants, there appears to be a link between visual arts-based education and improved oral abilities. Throughout the intervention stage, learners' improved ability to recognize, understand, and reproduce the target language is evident in the tasks proposed according to the guidelines suggested for first graders by the PEAP curriculum [3] and Halliday's Model of Language Functions [52].

Learners were guided to spontaneous speech creation in the first theme area as they attempted to identify colors and shapes in Paul Klee's painting "Castle and Sun." This is consistent with reference [25] suggesting that a dialogic interaction with an artwork may engender purposeful communication leading to oral language development. The majority of the students were able to name the colors they used in the post-speaking stage of the second teaching session, when they were asked to talk about some crafts, which they had made, and which were inspired by a certain artwork. Moreover, two of them were able to use the dark and light shades of the colors exploited and responded to more complicated questions asked by their teachers thus revealing a significant improvement in the speech production of the participants of the experimental group.

In the next thematic area, concerning numbers from one to five, learners seemed to understand the questions asked by the teachers in the target language concerning the content of the paintings. However, they responded to them using single vocabulary items. Nevertheless, what must be noticed is that, as instruction continued, the teachers rarely used the students' mother tongue in order to clarify the meaning of the questions addressed to the learners thus revealing a progress on their ability to communicate in the target language. Regarding the third and the fourth thematic areas, emphasis was placed on developing learners' abilities to express themselves by using their senses. For this reason, the learners were invited to imagine themselves in the different paintings and to talk about what they could see, hear, smell, taste, or touch, in the paintings. Learners' different receptive channels of knowledge were activated, which facilitated some of them to use more complex structures to describe the paintings.

Moreover, concerning the fourth thematic area which dealt with jungle animals and which included action verbs, learners seemed to be enchanted by Henri Rousseau's painting, "A tiger in 
a tropical storm", depicting an angry tiger deep in the African jungle. In their attempt to make guesses about the intentions of the tiger, learners were led to a spontaneous use the English language. According to references [31] and [40], special paintings which are characterized by physiological elements and an exciting vision of the universe can be employed, successfully, as a vibrant canvas for learners to discover new words and, eventually, to be able to use them.

As time went on, it was noticed that learners were gaining a better understanding of the teachers, who gradually reduced their use of the mother tongue in class, allowing them (that is the learners) to improve their oral fluency. For example, practically all learners were able to use and respond to the sound of the words "happy", "sad", "angry", and "scared", in a variety of exercises relating to Mark Rothko's paintings "Color Fields", in the first thematic area dealing with feelings.

Learners used all of their senses to interact with the paintings in the last thematic area, which dealt with the four seasons, by tasting fruit and dressing in the manner in which the figures representing the four seasons were dressed, as shown in Yannis Tsarouchi's painting "The four seasons". Learners spontaneously employed terminology related to the fruits portrayed in the artwork, demonstrating that young "learners can learn more effectively when information is physically, vocally, and visually linked" [32].

This is also supported by the outcomes of the post-semi structured interview, which revealed that learners believed that working with art paintings helped them utilize more English words and phrases. More specifically, fourteen learners in the experimental group stated in the fourth axis of the post-semi structured interview, about the impact of visual arts-based instruction on the development of learners' oracy skills, that their interaction with the paintings helped them to remember new words and phrases better, while presenting their own crafts, related to the paintings, helped them to remember new words and phrases better. This is in line with reference [28] claiming that learners' multisensory relationship with the visual arts may help them interact more intensely with the material, which they have been given by their teachers, and to retain the new knowledge, which they have acquired, in their long-term memory for longer periods of time, whereas presenting their own paintings also prompts students to use English effectively in their attempt to communicate their own work [25].

\subsection{Research Question 2: How do visual arts enhance vocabulary learning and use in first grade learners?}

The second research question was about the effects of visual-arts-based training on the development of vocabulary in young learners. The intervention was designed to promote the development of learners' receptive and productive vocabulary. The quantitative data was collected using a pre- and post-vocabulary development test given to both groups at the start and conclusion of the intervention stage. While-vocabulary development tests were also given to both groups throughout the intervention stage. In addition, qualitative data was obtained using audio recordings, the teachers' journal, and learners' replies to vocabulary acquisition questions, in the post-semi structured interview.

According to the quantitative analysis, there were no statistically significant differences in vocabulary growth between the control and the experimental groups prior to the intervention stage. By contrast, an independent sample test reported significant differences between the performances of the two groups at the end of the intervention stage. More specifically, the experimental group improved substantially between the pre- and post- instruction stage, while the control group showed no improvement at all (Table 1). 
International Journal on Integrating Technology in Education (IJITE), Vol.10, No.4, December 2021

Table 1. Pre-and post-vocabulary development differences within each group.

\begin{tabular}{llllll}
\hline Vocabulary development & Measurement & $M(\%)$ & $S D$ & $t$ & $p$ \\
\hline Experimental group & Pre-intervention & 8.33 & 1.85 & 18.036 & .000 \\
& & & & & \\
& Post-intervention & 11.44 & 0.62 & 72.717 & .000 \\
\hline Control group & Pre-intervention & 8.69 & 1.25 & 27.800 & .000 \\
& Post-intervention & 8.69 & 1.25 & 27.800 & .000 \\
\hline
\end{tabular}

An independent sample test revealed no statistically significant differences between the control and experimental groups when it came to the mean score of the while-intervention vocabulary development tests given to the control and experimental group. The descriptive statistics, on the other hand, revealed that the experimental group outperformed the control group in all of the vocabulary development assessments (Table 2).

Table 2. While-vocabulary development differences between the groups.

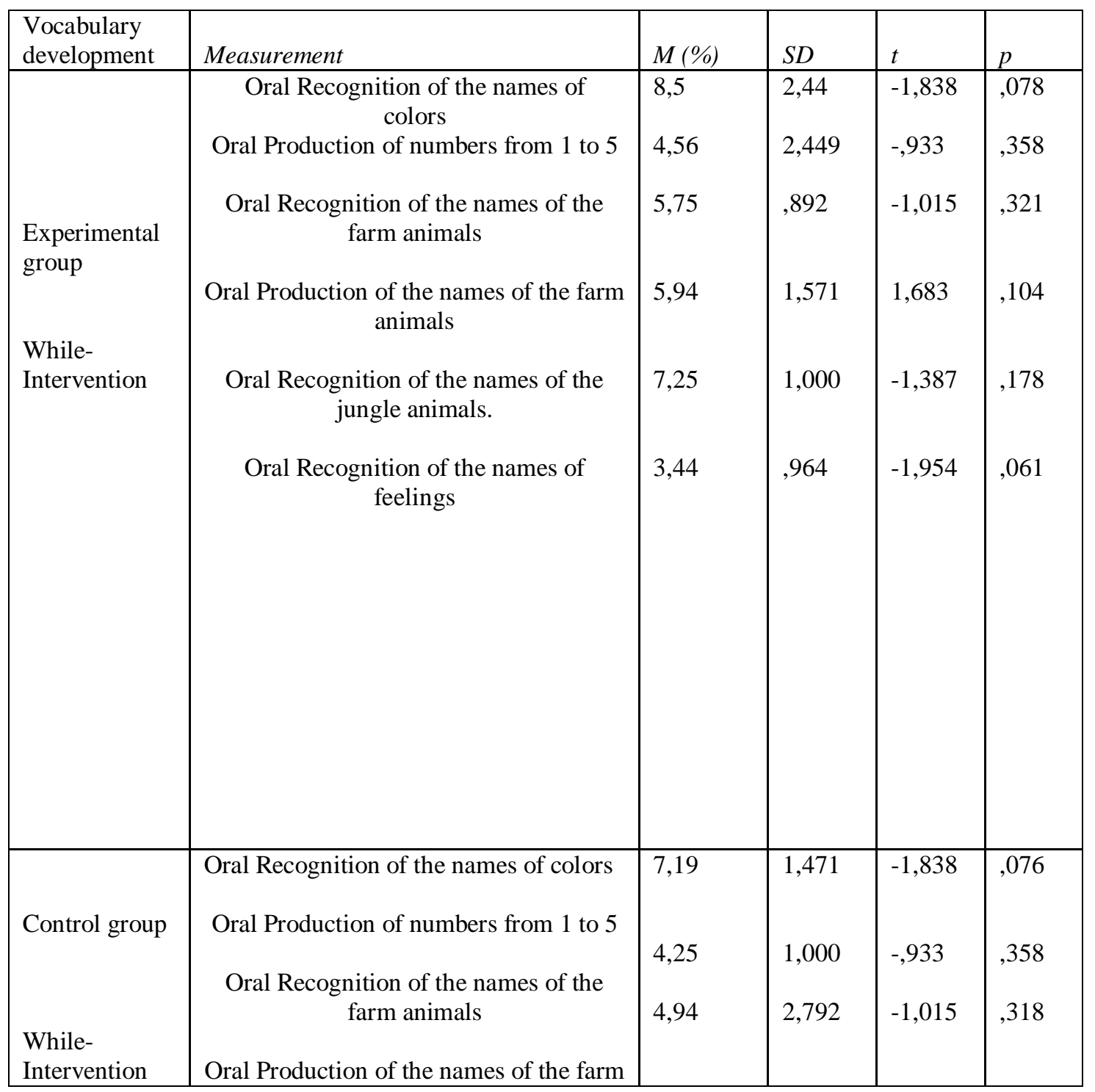


International Journal on Integrating Technology in Education (IJITE), Vol.10, No.4, December 2021

\begin{tabular}{|c|c|c|c|c|c|}
\hline animals & 4,69 & 2,469 & 1,683 &, 103 \\
& $\begin{array}{c}\text { Oral Recognition of the names of the } \\
\text { jungle animals. } \\
\text { Oral Recognition of the names of } \\
\text { feelings }\end{array}$ & 2,69 & 1,195 & $-1,954$ &, 060 \\
\hline
\end{tabular}

More specifically, the experimental group's participants scored higher, on average, than the control group's learners in their attempt to orally recognize and produce the names of the colors, which is consistent with Eisner's belief that creativity through art allows for deeper degrees of knowledge [27]. In the second thematic area, the experimental group outperformed the control group on average when it came to producing numbers from one to five. This is in line with reference [53] suggesting that learners are taught to integrate and decode information in paintings through visual arts, hence boosting vocabulary learning and visual literacy. In terms of oral recognition and production of farm animals, the experimental group appeared to score higher on average than the control group, indicating that first-graders' capacity to utilize language to transmit knowledge and express what they know is gradually improving [52]. The experimental group appeared to outperform the control group in recognizing the names of jungle animals in the fifth thematic area. This is in line with reference [54] claiming that the engagement of multiple senses results in the activation of all of them, accessing memory building channels in the brain which allow learners to reach conceptual retention and achievement of objectives while they are fully engaged in the learning process [54]. The situation was similar in the fifth thematic area as the participants in the experimental group scored on average higher than the participants in the control group in their attempt to recognize the names of feelings, supporting Baine's basic claim that learners can master abstract language by simulating senses [28].

The results of the tests, as well as a careful examination of the recordings and the teachers' journals show that the experimental group showed significant progress in terms of vocabulary acquisition and retention. For example, during the post-speaking stage of the first theme area, two learners were able to manage all of the varied hues of colors which were used in their structures. This supports the concept that learners are led to inadvertent language acquisition when they are assigned creative crafts to express the knowledge which they had acquired from the paintings [42]. Moreover, during the third and fourth thematic areas, most learners were able to recall and use all of the vocabulary taught about sizes, farm animals, and jungle animals. Learners appeared to be able to recognize and create all of the animals encountered in the paintings, used as prompts in the various subject regions, indicating that paintings can be utilized as a mnemonic tool to aid memory a "long term consolidation of linguistic content" as Dobos calls it [41]. Furthermore, learners expressed their preferences for the paintings used in the specific thematic areas, as well as their liking for the follow-up crafts and constructions, according to information obtained from the post-semi structured interview investigating learners' attitudes toward art-based instruction. This is in line with the belief that young learners tend to remember and use just what attracts and makes sense to them [37], [38]. Additionally, learners stated that discussing their own crafts in relation to their favorite themes of the paintings helped them retain new words associated with their crafts.

\subsection{Research Question 3: How do visual arts enhance language chunks learning and use in first grade learners?}

The final research question looked into the impact of visual arts on the development of language chunks and phrases which are used by young learners in their speaking. Participants in both 
groups underwent a language chunks development test before and after the intervention stage to answer to this question. During the intervention stage, they were also given three language chunks-development exams. The test results were statistically evaluated to see if there were any variations in performance between the two groups. Quantitative data was also collected through the audio recordings of the lessons, the teachers' diaries as well as the learners' responses to the questions referring to language chunks development, the aforementioned were also conducted in the post-semi structured interview.

In a similar vein, an independent sample test reported no significant differences between the performances of the two groups, at the end of the intervention stage, as well. In the post-language development test, however, participants in the experimental group scored, on average, higher than those in the control group. More particularly, the experimental group improved significantly between the pre- and post-instruction stages, whereas the control groups' participants improved only somewhat (Table 3 ).

Table 3. Pre- and post- intervention differences on language chunks development within each group.

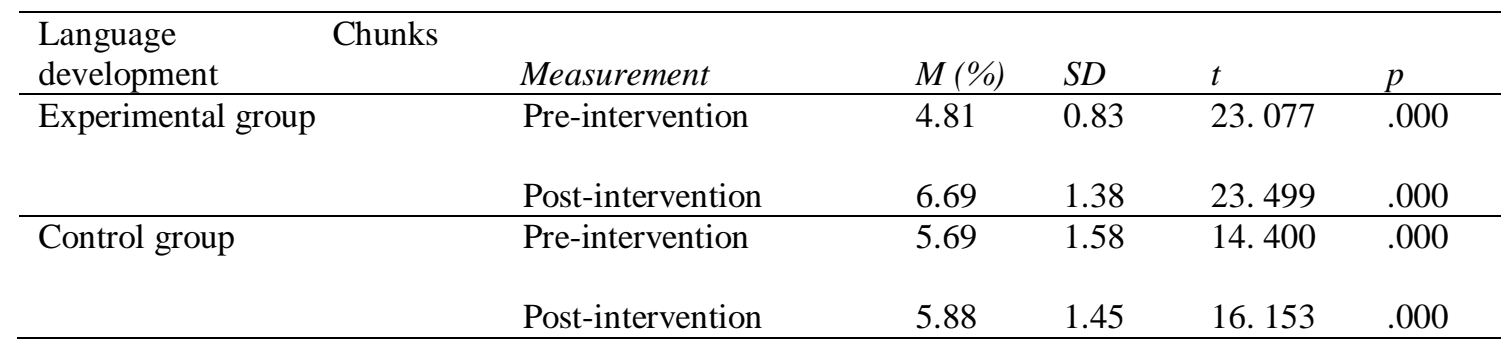

An independent sample test revealed no statistically significant differences between the control and experimental groups in the outcomes of the means of the while-intervention language chunks development tests given to both groups. However, the descriptive statistics revealed a pattern in which the experimental group outperformed the control group in all language chunk development assessments (Table 4).

In the fourth thematic area, the experimental group appeared to score higher, on average, than the control group in their attempt to respond to larger units of words describing wild animal action thus indicating that shifting information from visual imagery to language and back again improves learners' understanding [55]. Similarly, the experimental group appeared to outperform the control group when it came to producing larger units of words to represent feelings. This indicates that "working with something that is concrete such as art to something abstract such as language encourages learners to link their own experiences" [55] and to be able to produce simple sentences in the target language [54]. In a similar vein, the experimental group appeared to score higher, on average, than the control group in their attempt to talk about weather conditions using formulaic language in the last theme area. This could show that learners can grasp and apply simple language chunks to describe themselves and others through practice exercises that use the senses as a learning tool. 
International Journal on Integrating Technology in Education (IJITE), Vol.10, No.4, December 2021

Table 4. Language development differences between the two groups.

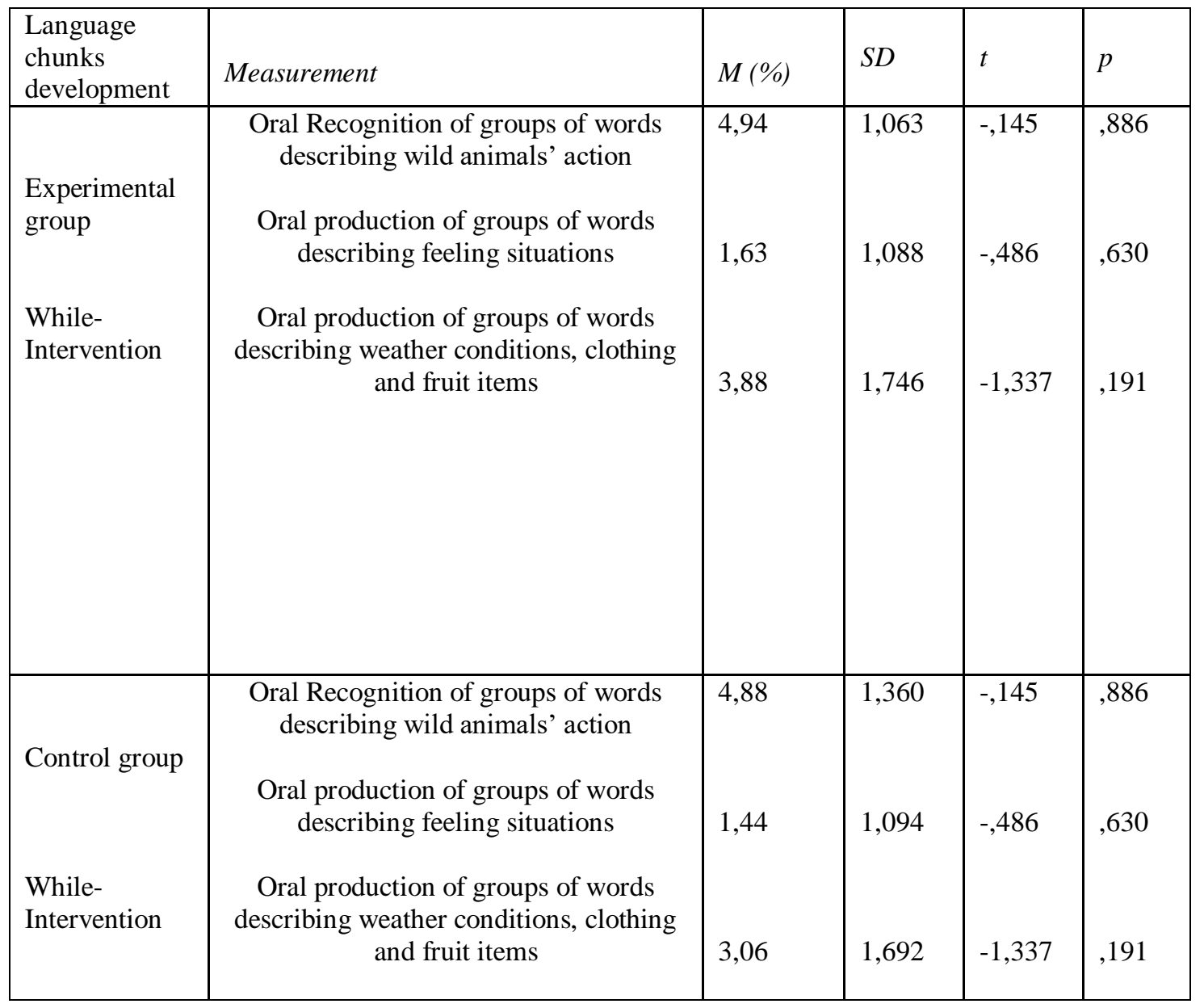

\section{DisCUSSION}

The findings from the first research question appear to support the hypothesis that visual arts can help young learners improve their oral production skills by providing them with rich and relevant input that can serve as a springboard for them to become more actively involved in the learning process [22]. It is clear that visual arts can aid in the formation of a welcoming and comfortable learning environment in the English classroom, encouraging students to open their filters and engage in spontaneous and natural speech production [10], [56].

In terms of vocabulary uptake, the findings suggest that there is a link between young learners' exposure to visual arts and vocabulary acquisition leading to improved oral development, as the experimental group's participants appeared to have acquired and retained a greater number of vocabulary items in their long-term memory than the control group's participants. This conclusion is consistent with earlier research on the favorable impact of visual arts on the development of young learners' vocabulary. According to reference [42], visual arts encourage learners to make educated assumptions and to draw conclusions based on what they observe, which improves understanding and recall of educational material.

Observing and understanding visual arts such as paintings can be an effective way to elicit new words, information, and to aid learners in developing a mental vocabulary [18]. Finally, reference [37] emphasized the necessity of allowing young learners to associate a term with an 
object, thing, or actual person in order to increase their vocabulary. The current study's contribution is that visual arts can be used as a springboard for vocabulary growth, allowing students to connect living visuals with words.

In terms of formulaic uptake, it's possible that learners' involvement with visual arts and sensory activation influenced language chunk formation, as the learners of the experimental group appear to have acquired a greater number (of units) of words, with which they had met up during the teaching stage, compared to the control group. For example, many exercises encouraged learners to employ a variety of senses, allowing them to identify with the scenarios presented and to construct larger units of speech without formal language training [38], [45] and [44]. Learners were given the opportunity to associate learnt expressions with images of concrete scenes via paintings, which helped them to remember the aforementioned better in the long run [47].

\section{Limitations OF THE Study AND Suggestions For Further RESEARCH}

Although the conclusions that were drawn earlier indicate that there was an improvement in the learners' oracy skills, there are limitations to the specific study in terms of the time duration and the number of the learners who participated in the intervention. More specifically, the specific intervention program lasted only for two months as there was a restriction placed, by the government of Greece, on the time limit, due to the Covid-19 pandemic which did not allow for a further implementation of the specific intervention. However, an extension of the duration of the intervention might allow for more valid results concerning the effectiveness of the program. Another issue for consideration are the number of learners who participated in the experiment. Both the control and the experimental group consisted of sixteen learners each of which constitutes a small number and does not allow for the generalization of the findings. Perhaps, a larger scale sample could provide us with more reliable findings concerning the effect of the specific approach to first grade learners' oral abilities. However, the results of this small-case research cannot be disregarded as they indicate that the use of visual arts can have a considerably positive effect on young learners' receptive and productive oracy skills.

In fact, the particular findings indicate that art-based instruction may indeed have a remarkable linguistic and pedagogical value in a primary school EFL class, thus testifying to a positive influence, not only on the development of young learners' oracy skills and language awareness, but also on the enhancement of learners' responses concerning the world which surrounds them, and on their representation of the world [16]. The aforementioned facilitates young learners to master the required capacities, and content knowledge areas, through active exploration, and through hands-on learning experiences [9], [10]. It thus becomes evident that, art-based instruction should be incorporated into the PEAP curriculum as it has much to offer, not only on the enhancement of young learners' oracy skills, but also on the well-rounded development of young learners. Enabling them to understand the world they live in and providing them with ample avenues for comprehension and communication [15]; the visual art-based approach might emerge as an invaluable tool for teachers, at all levels of learning, to enhance instruction for English language learners. These results are in accordance with other studies which have been aforementioned and which clearly depict the effectiveness of visual arts in the teaching and learning process of very young learners. The teaching of a foreign language, through visual arts, could lead to an increase of the capacity of young learners to achieve success, not only in verbal communication but also in other academic areas and skills such as reading and writing. It would also be interesting, in a future research study, to investigate the arts through apps in our mobile phones [57]. 
International Journal on Integrating Technology in Education (IJITE), Vol.10, No.4, December 2021

\section{Conclusion}

Very few empirical research studies have been conducted in Greece concerning the impact of visual arts-based training on the improvement of English language teaching and learning, particularly the development of pre-A1 level learners' speaking abilities. The specific research aimed to investigate the impact of the particular approach using artistic elements on the oral receptive and productive skills of learners in the first grade of a Primary school in a small provincial town in Greece.

The results show that visual-arts-based education has a positive impact on the oral abilities of the participants in the experimental group as compared to those in the control group. The findings of the tests, as well as the observation of the classes, suggested that visual-arts-based instruction had an impact on vocabulary acquisition and formulaic uptake. Finally, the data acquired from the learners' interviews suggested that the visual arts-based instruction, both in terms of the paintings used and the follow-up speaking activities and crafts, was well received by the students.

\section{ACKNOWLEDGEMENTS}

I would like to thank all the participants for their support in contributing to this project.

\section{Disclosure Statement}

No potential conflict of interest was reported by the authors.

\section{REFERENCES}

[1] A. Delliou and M. Zafiri, "Developing the speaking skills of students through CLIL," Proceedings of The 5th Electronic International Interdisciplinary Conference, 2016.

[2] K. Silver, "Supporting oracy development in pre-school EFL students", 2020. [Online]. Available: https://www.cambridge.org/elt/blog/2020/10/13/oracy-6-supporting-early-oracy-development-inpreschool-elt-students/

[3] V. Dendrinos, "The PEAP programme: English for young learners in the Greek primary school". Athens: Research Centre for Language Teaching Testing and Assessment (RCeL), National and Kapodistrian University of Athens, 2013.

[4] P. S. Rao, "The importance of speaking skills in English classrooms". Alford Council of International English \& Literature Journal (ACIELJ), vol:2, no:2, pp. 6-18, 2019.

[5] R.Jack and M. Richards, Teaching listening and speaking from theory to practice. Cambridge University. Printed in The United States of America, 2008.

[6] T. Alexiou, "Young learners' cognitive skills and their role in foreign language vocabulary learning". In M. Nikolov (ed.) Second Language Acquisition: Early Learning of Modern Foreign Languages. Processes and Outcomes, pp. 46-61, 2009. Bristol: Multilingual Matters.

[7] M. C. Zardini and F. H. L. Barnabe, F. H. L. "How to improve the speaking skills through the communicative approach.", Journal of Language Teaching, vol: 9, no: 2, 2013.

[8] R. Taylor, "Using Art in the ESL". Classroom. Introduction to Teaching Overseas, 2015. [Online]. Available: https://www.eslbase.com/teaching/using-art-esl-classroom

[9] P. J. Ruiz, "Art as a tool for teachers of English language learners". New York, The New York State Education Department Office of Bilingual Education and Foreign languages Studies/University of The State of New York, 2010.

[10] J. Dewey, Experience and education. New York: Simon and Schuster, 1938.

[11] B. Wandell, R.F. Dougherty, M. Ben-Shachar, G. K. Deutsch and J. Tsang, J, "Training in the arts, reading, and brain imaging". Learning, arts, and the brain, vol: 51, 2008. Available: https://dana.org/wp-content/uploads/2013/12/learning-arts-and-brain-dana-press.pdf

[12] R. Kennedy, "Guggenheim Study Suggests Arts Education Benefits Literacy Skills". New York Times, 2006. [Online]. Available: https://www.nytimes.com/2006/07/27/books/27gugg.html 
International Journal on Integrating Technology in Education (IJITE), Vol.10, No.4, December 2021

[13] P. Havé, "The use of art in English language teaching: Developing learners' receptive and productive skills by engaging with masterpieces from classical to modern art". Le government du Grande-Duché du Luxembour, 2013.

[14] S. Thornbury, "An AZ of ELT concepts", 2006.

[15] M. Farokhi and M. Hashemi, "The impact/s of using art in English language learning classes". Procedia-Social and Behavioral Sciences, vol: 31,pp. 923-926, 2012.

[16] L. H. Chapman, Approaches to art in education. Harcourt College Pub, 1978.

[17] J. H. Davis, Why our schools need the arts. New York: Teachers College Press, 2008.

[18] C. Schander, B. Balma, and A. Massa, "The joy of art in the EFL classroom". European Scientific Journal, vol: $2, \quad$ pp. $\quad 409-414$ 2013. [Online]. Available: https://eujournal.org/index.php/esj/article/view/2380

[19] M. Timuçin and H. Aryoubi, "Integrating arts in EFL curricula: A focus on language listening skills". International Journal of Languages' Education and Teaching, vol: 4, no: 2, 2016.

[20] N. Chang and S. Cress, "Conversations about visual arts: Facilitating oral language". Early Childhood Education Journal, vol: 42, no: 6, pp. 415-422., 2014.

[21] H. Gardner, Frames of mind: The theory of multiple intelligences. New York, NY: Basic Books, 1938.

[22] A. Flory, "Exploring the Benefits of Art in Elementary Education", 2005.

[23] I. Abukhattala, "Krashen's Five Proposals on Language Learning: Are They Valid in Libyan EFL Classes". English Language Teaching, vol: 6, no:1, pp. 128-131, 2013. [0nline]. Available: https://eric.ed.gov/?id=EJ1076806

[24] A. M. Galti,, "Effect of Suggestopedia Method in Teaching Vocabulary to Primary School Students". AL-MUQADDIMAH, A Journal of the Humanities, Law, Social \& Management Sciences, vol:1, no:1, 2018.

[25] J. .M. Iorio, "Rethinking conversations. Contemporary Issues in Early Childhood", vol: 7, no: 3, pp. 281-289, 2006. [Online]. Available: https://journals.sagepub.com/doi/abs/10.2304/ciec.2006.7.3.281

[26] E. Zimmerman, "Review-Chapman Approached to ArtED." Studies in Art education, vol.21, no. 2, pp. 70-71, 1980.

[27] E. W. Eisner, The arts and the creation of mind. Yale University Press, 2002.

[28] L. Baines, A teacher's guide to multisensory learning: Improving literacy by engaging the senses. ASCD, 2008.

[29] C. Chi, "Integrating the arts into English learning: A case study of EFL learners in a Canadian university". Doctoral dissertation, University of Windsor (Canada), 2017. [Online]. Available: https://scholar.uwindsor.ca/cgi/viewcontent.cgi?article=6976\&context=etd

[30] T. Alexiou and M. Stathopoulou, "The Pre-A1 Level in the Companion Volume of the Common European Framework of Reference for Languages". Research Papers in Language Teaching and Learning, vol. 11, no1, pp. 11-29.,2021.

[31] D. Voto, L. Viñas, and L. D’Auria, L. "Multisensory interactive installation". Sound and Computing, vol: 5, pp. 24-26, 2005. [Online]. Available: http://smc.afimasso.org/smc05/papers/DanielaVoto/MII\%20Paper\%20Salerno.pdf .

[32] S. YMousavi, S. Y., Low, R., \& Sweller, J. (1995). Reducing cognitive load by mixing auditory and visual presentation modes. Journal of educational psychology,87(2), 319. Available at: https://www.semanticscholar.org/paper/Reducing-cognitive-load-by-mixing-auditory-and-MousaviLow/cd8931e3d167ef7fabe70f2f7d933ce6c4b8dff4 (accessed 21 March 2021).

[33] Hernández, K. , Martínez, A. , Muñoz, C. (2017). Teaching English through multisensory activities in a public school. Available at: https://core.ac.uk/download/pdf/159377891.pdf, (accessed 19 March 2021).

[34] S. Celik Korkmaz and C. Karatepe, "The Impact of Multi-Sensory Language Teaching on Young English Learners' Achievement in Reading Skills". Novitas-ROYAL (Research on Youth and Language), vol: 12, no:2, pp. 80-95, 2018.

[35] C. Ylla Esteve, “Very young learners' vocabulary development in English: a case study with 4 and 5 year-old children”, 2016.

[36] P. Meara, "The dimensions of lexical competence". Performance and competence in second language acquisition, vol: 35, pp. 33-55, 1996.

[37] T. Alexiou, "Vocabulary uptake from Peppa pig: a case study of preschool EFL learners in Greece. In C. Gitsaki, \& T. Alexiou (Eds.) Current Issues in Second/foreign Language Teaching and Teacher 
International Journal on Integrating Technology in Education (IJITE), Vol.10, No.4, December 2021

Development: Research and Practice,. Newcastle upon Tyne, UK: Cambridge Scholars Publishing, 2015, pp. 285-301.

[38] L. Cameron, Teaching Languages to Young Learners. Cambridge: Cambridge University Press, 2001.

[39] J. Keddie, "Using Art in the Classroom. MacMillan Publishers Lt", 2010. [Online]. Available: https://www.onestopenglish.com/general-english/using-art-in-the-classroom/550072.article

[40] E. Hatch, and C. Brown, Vocabulary, semantics, and language education. Cambridge University Press, 40 West 20th Street, New York, NY 10011-4211 (hardback: ISBN-0-521-47409-4; paperback: ISBN-0-521-47942-8), 1995.

[41] I. D. Dobos, "Using Art as a mnemonic tool for language acquisition in the EFL class", 2020. [Online]. Available : https://twinklestar.ro/using-art-as-a-mnemonic-tool-for-language-acquisition-inthe-efl-class/

[42] Y. Gidoni and M. Rajuan, " The use of drawing tasks as a creative strategy for pupils in the English as Foreign Language (EFL) classroom". Journal of Second Language Teaching \& Research, vol: 6, no: 1, pp. 5-19, 2018. [Online]. Available: https://pops.uclan.ac.uk/index.php/jsltr/article/view/483

[43] L. Hoyt, "Many ways of knowing: Using drama, oral interactions, and the visual arts to enhance reading comprehension". The Reading Teacher, vol:45, no:8, pp. 580-584, 1992. [Online]. Available: https://www.jstor.org/stable/20200932?seq=1

[44] C. Becker and J. Roos, "An approach to creative speaking activities in the young learners' classroom". Education Inquiry, vol: 7, no: 1, 2016. [Online]. Available: https://www.tandfonline.com/doi/full/10.3402/edui.v7.27613

[45] T. Alexiou, M. Mattheoudakis, D. Saratsli and A. Vagenas, A. "Words don't come easy: Linguistic analysis of vocabulary in Magic Books". Journal of Applied Linguistics, vol: 32, pp. 25-41, 2019. [Online]: Available: http://ejournals.lib.auth.gr/jal/article/view/7515

[46] H. Men, Vocabulary increase and collocation learning: A corpus-based cross-sectional study of Chinese learners of English. Springer, 2017. [Online] Availabe: http://www.openaccess.bcu.ac.uk/3870/1/2015_Men_646025.pdf

[47] F. Boers, "Learning lexical phrases". The Cambridge Guide to Learning English as a Second Language, vol: 176, 2018. [Online]. Available: https://books.google.gr/books?hl=el\&lr=\&id=5MtQDwAAQBAJ\&oi=fnd\&pg=PA176\&dq=oers,+F. +(2018).+Learning+lexical+phrases.+\&ots=1B7bOoIHQg\&sig=L14w3CzuoHXix9NUB1PufRnXwQ o\&redir_esc $=\mathrm{y} \# \mathrm{v}=$ onepage $\& \mathrm{q} \& \mathrm{f}=$ false

[48] J. M. Clark and A. Paivio "Dual coding theory and education". Educational psychology review, vol: 3, no: 3, pp. 149-210, 1991. [Online]. Available: http://nschwartz.yourweb.csuchico.edu/Clark\%20\&\%20Paivio.pdf

[49] R. Sagor, The action research guidebook: A four-stage process for educators and school teams. Corwin Press, 2011.

[50] E. Ferrance, "Themes in education: Action research". Brown University: Educational Alliance, vol: 34, no: 1, pp. 1-33, 2000.

[51] E. P. Jack and A.S. Raturi, "Lessons learned from methodological triangulation in management research". Management research news., 2006.

[52] M. A. K. Halliday, Explorations in the Functions of Language. London: Edward Arnold, 1973.

[53] N. Bryce, "Mano a Mano: Arts-Based Nonfiction Literacy and Content Area Learning". Language Arts, vol:89, no:3, p. 179.,2012. [Online]. Available: https://www.proquest.com/openview/f6772d80faf645a3684c8133c1a442bf/1?pqorigsite $=$ gscholar \&cbl $=41436$

[54] N. S. Algrni, "The Effectiveness of Using Multisensory Approach in Enhancing Achievement and Retention of English Vocabulary Amongst Intermediate Female Students with EFL Learning Disabilities". Journal of Education and Practice, vol: 11, no: 9, 2020.

[55] B, Gorjian, A. Hayati and E. Barazandeh, "An evaluation of the effects of art on vocabulary learning through multi-sensory modalities”. Procedia Technology, vol: 1, pp. 345-350, 2020. [Online]. Available at: https://core.ac.uk/download/pdf/82084367.pdf

[56] S. Krashen, Principles and practice in second language acquisition. Oxford: Pergammon, 1982.

[57] S. Papadakis, "The impact of coding apps on young children Computational Thinking and coding skills". A literature reviews. In Frontiers in Education Vol. 6, pp. 183, Frontiers, 2021. 
International Journal on Integrating Technology in Education (IJITE), Vol.10, No.4, December 2021

\section{AUTHORS}

Eirini Kikioni works for the Greek Ministry of Education and Religious Affairs and she is a permanent English Language Teacher at the $11^{\text {th }}$ Primary State School in Agrinio, Aitoloakanania, Greece.

Makrina-Nina Zafiri is permanent at the Aristotle University of Thessaloniki, Department of Foreign Languages, she is also an Academic Associate at the Hellenic Open University, and a Teacher Trainer at the Greek National Training Center of ASPAITE in Thessaloniki, Greece. 